\title{
La objeción de conciencia del menor en los tratamientos médicos
}

Oscar Díaz Muñoz

\section{La objeción de conciencia en los tratamientos médicos}

La objeción de conciencia consiste en la negativa del individuo a someterse a una conducta que en principio sería jurídicamente exigible (ya provenga la obligación de una norma, de un contrato, de un mandato judicial o resolución administrativa), por razones axiológicas - un deber para su conciencia, diverso del planteamiento puramente psicológico de quien transgrede la norma para satisfacer un capricho o un interés bastardo-, de contenido primordialmente religioso o ideológico, con el objeto de elegir lo menos lesivo para la propia conciencia entre las alternativas previstas por la norma, eludir el comportamiento contenido en el imperativo legal o la sanción prevista por su incumplimiento, o incluso, aceptando el mecanismo represivo, lograr la alteración de la norma que es contraria al personal imperativo ético. ${ }^{1}$

La objeción de conciencia puede encontrarse en diversos escenarios. Entre sus principales manifestaciones está la objeción al servicio militar obligatorio; la objeción de conciencia a los tratamientos médicos, que se presenta ante prácticas sanitarias que se imponen de manera necesaria para preservar la salud o la vida; la objeción de conciencia al aborto, que consiste en la negativa, generalmente del personal sanitario, a participar de modo directo o indirecto en prácticas abortivas; la objeción de conciencia fiscal, que es el rechazo al pago de aquella parte de los tributos cuyo des-

1 R. Navarro-Valls y J. Martínez-Torrón, Las objeciones de conciencia en el derecho español y comparado, Madrid, 1997, p. 14. 
tino final establecido por la autoridad repugna a la conciencia del contribuyente; la objeción de conciencia en el ámbito laboral, que se da en aquellas situaciones en las que un trabajador se niega, por razones de conciencia, a cumplir una obligación que se deriva de su relación de trabajo. ${ }^{2}$

Definitivamente, la objeción a los tratamientos médicos es la más polémica y la que ha demando constantes reflexiones de la doctrina y la jurisprudencia, pues suele comprometer bienes tan valiosos como la salud o la vida. Sin ser las únicas, dos son las principales confesiones religiosas que han dado origen a estos conflictos: ${ }^{3}$ los testigos de Jehová, que consideran la ingestión de sangre vetada por una prohibición divina, a través de una interpretación de ciertos pasajes de la Biblia, ${ }^{4}$ y la Christian Science, cuyos seguidores creen que cualquier dolencia puede ser sanada exclusivamente mediante la oración, y rechazan el recurso a los tratamientos médicos de manera generalizada. ${ }^{5}$

La objeción de conciencia a los tratamientos médicos está prevista legislativamente en el Derecho español —desde donde abordaremos el problema materia de este trabajo-, ya que el Art. 10.6 de la Ley No 14/ 1986, de 25 de abril, Ley General de Sanidad, exige el consentimiento informado del paciente de modo previo a la práctica médica. Este consentimiento podría negarse a través de la objeción de conciencia, lo que haría que la intervención médica no pueda llevarse a cabo. En tales casos, sería necesario acudir al Juez para intentar vencer la objeción del paciente.

Pero la Ley General de Sanidad deja claro también que las situaciones de urgencia eximen de la obligación de recabar el consentimiento informado (Art. $10^{\circ} .6 . c$ ), por lo que, en esas circunstancias, no obstante la objeción de conciencia del paciente, el tratamiento podría practicarse, sin necesidad de la previa autorización judicial.

Antes de pasar a tratar la objeción formulada por un menor, mencionaremos lo que acontece cuando el objetor es un adulto, pues lo que se diga en este caso nos servirá para conocer ideas generales de este tipo de objeción de conciencia.

2 Cfr., por todos, R. Palomino, Las objeciones de conciencia, Madrid, 1994.

3 R. Navarro-Valls, "Las objeciones de conciencia», en: J. Ferrer Ortiz (Coord.), Derecho Eclesiástico del Estado Español, Pamplona, 1996, p. 209.

4 «Si un israelita o un extranjero residente entre vosotros come cualquier clase de sangre, yo me volveré contra él y lo extirparé de su pueblo" (Levítico XVII, 10). Cfr., también, Hechos XV, 28-29.

5 R. Navarro-Valls y J. Martínez-Torrón, Las objeciones [...], op. cit., p. 120. 
Un criterio jurisprudencial que puede encontrarse especialmente en Estados Unidos - país en el que mayor protección ha encontrado la negativa a tratamientos médicos por razones de conciencia-, es distinguir entre el objetor con hijos y el objetor sin hijos o personas dependientes de él.

Tratándose de un adulto sin hijos, se sostiene que debería respetarse su decisión de no autorizar el tratamiento médico, aunque tal opción le conduzca a la muerte. ${ }^{6}$ Sin embargo, esta regla presenta importantes excepciones, en casos que tienen la virtualidad de hacer surgir el interés público que justifique la imposición del tratamiento por mandato judicial. Como dice Regueiro García, cuando las creencias religiosas del paciente impidan un tratamiento de modo que se vea perjudicada la salud pública (negativa a una cuarentena, vacunación, etc.), debería llevarse a cabo la intervención médica. ${ }^{7}$

Pero lo mismo podríamos decir cuando estamos frente a un objetor adulto con hijos o personas que dependan de él. Es así que la jurisprudencia norteamericana entiende que una excepción a la regla del respeto de la decisión del objetor adulto, es la existencia de una familia que dependa económica, educativa y afectivamente de la supervivencia de este. ${ }^{8}$

La situación varía cuando el enfermo adulto se encuentra incapacitado para tomar una decisión. Es también la jurisprudencia norteamericana la que ha afrontado el supuesto de objeción de conciencia del adulto en estado de incapacidad - non compos sui-, que no puede tomar por sí mismo una decisión con valor jurídico. Fuera de las situaciones de peligro de muerte, en las que se suele autorizar la imposición del tratamiento médico, las cortes estadounidenses han elaborado una doctrina denominada "juicio de sustitución» (substituted judgement), según la cual, en síntesis, se trata no de reemplazar la decisión del incapaz por la de una persona "normal», sino de intentar precisar cuál hubiera sido la decisión del paciente de haberse encontrado en condiciones normales de decidir por sí mismo. Así, el paciente que actúa movido por motivos de conciencia, puede haber tomado una decisión que responde a una trayectoria,

6I. Durany Pich, Objeciones de conciencia, Pamplona, 1998, p. 23.

7 M.T. Regueiro García, "Libertad religiosa del paciente en tratamiento médico", en: V. Guitarte Izquierdo y J. Escrivá Ivars, La objeción de conciencia. Actas del VI Congreso Internacional de Derecho Eclesiástico del Estado, Valencia, 1993, p. 364.

8 R. Navarro-Valls y J. Martínez-Torrón, Las objeciones [...], op. cit., p. 124. 
a su propia concepción de la vida, de acuerdo con la cual hay valores que le trascienden y no es imaginable presumir que la hubiera cambiado de volver a ser consciente; por lo que en el supuesto de pérdida de conciencia, en el caso de la objeción a la hemotransfusión, deberían aplicarse todas las medidas disponibles, salvo la de la transfusión.?

Algunos suelen presentar la objeción de conciencia a los tratamientos médicos como un caso de conflicto entre la vida y la libertad religiosa, asemejándola a un supuesto de suicidio. Sin embargo, un sector de la doctrina sostiene que tal conflicto no existiría realmente, pues la objeción de conciencia de un adulto capaz, no constituye un intento de suicidio, un atentado contra la propia vida o la salud que deba evitarse. Así, señala Hervada que el rasgo característico del tipo que llamamos suicidio es la intentio sese occidendi, la intención de perder la vida. Donde no hay intentio occisiva no hay suicidio. Por eso, no basta que de hecho al sujeto le sea posible librarse de la muerte; no estamos en presencia de unas simples posibilidades técnicas o, si se prefiere, fácticas. Si le es de hecho posible librarse de la muerte pero a costa de un deber moral, no hay suicidio, si el sujeto, en cumplimiento de ese deber, no rehuye el peligro inminente de la muerte y como consecuencia de ello pierde la vida. Así, el prisionero de guerra a quien se pone en la alternativa de ser fusilado o cometer un acto de traición, no es suicida de ningún modo al rehusar traicionar a su patria, sabiendo el destino que le espera. En este caso, no existe intención de matarse, sino simple aceptación de la muerte, de la que al sujeto le resulta «imposible» - moralmente, aunque no fácticamente- huir. En una conducta moral, tan imposible resulta la imposibilidad física como la moral. De esta forma, cuando alguien está dispuesto a recuperar la salud o salir del peligro de muerte por todos los medios ordinarios y moralmente lícitos, no hay en él ninguna intentio sese occidendi, sino todo lo contrario. El rechazo de un tratamiento médico que se considera inmoral no incluye voluntad occisiva alguna, sino simple aceptación de los límites de la capacidad humana para recuperar la salud, ya que el medio inmoral es un medio de imposible uso, por imposibilidad moral. ${ }^{10}$

9C. M. Romeo Casabona, "Límites de la posición de garante de los padres respecto al hijo menor? La negativa de los padres, por motivos religiosos, a una transfusión de sangre vital para el hijo menor», en: Revista de Derecho Penal y Criminología 2 (1998), p. 355.

$10 \mathrm{~J}$. Hervada, «Libertad de conciencia y error sobre la moralidad de una terapéutica», en: Persona y Derecho, XI (1984), pp. 16-18. 
En similar sentido, Navarro-Valls y Martínez-Torrón dirán que la objeción de conciencia de un adulto capaz a un tratamiento médico contrario a su conciencia es una situación distinta de la hipótesis configuradora de la conducta suicida. En el horizonte intencional del suicida existe el contravalor de quitarse la vida. No hay en dicha conducta un valor que merezca la estima y tutela de la sociedad, por más que el suicidio en sí no sea legalmente punible. Pero en el objetor a un tratamiento médico por razones religiosas existen unos valores que merecen el respeto de la sociedad, aunque ésta no los asuma mayoritariamente. Su negativa al tratamiento médico no significa en modo alguno que busque conscientemente la muerte. Tan solo considera que no vale la pena conservar la vida a costa de perder - a su juicio- la salvación eterna, o bien juzga los medios sobrenaturales como los más adecuados - y los únicos lícitos-para obtener la curación. De ahí que resulte desenfocado enjuiciar estos supuestos desde la perspectiva de remediar un intento de suicidio. ${ }^{11}$

De opinión contraria es Romeo Casabona, para quien la negativa a un tratamiento médico por razones de conciencia se aproxima al suicidio. Refiriéndose a los testigos de Jehová afirma que «quieren vivir, pero sin transgredir su credo religioso, lo cual es muy respetable, se compartan o no tales creencias minoritarias. Sin embargo, cuando no existen otras alternativas terapéuticas (hipótesis que hay que aceptar como punto de partida para supuestos extremos, aunque probablemente aislados en la práctica) y la transfusión de sangre parece el único medio posible, desde un punto de vista objetivo, para eliminar el peligro inminente para la vida del paciente que pertenece a esa confesión religiosa, si por mantenerse fiel a ella persiste en rechazar la transfusión, hay que admitir que con tal actitud está contando con la posibilidad de morir, hay una voluntad de morir, al menos indirecta, si el paciente es consciente de que no existe otro medio de salvar su vida. Este contar con la producción del evento probable o seguro de la muerte se aproxima desde el punto de vista jurídico a una actitud suicida, en cuanto que aquella se presenta como consecuencia necesaria asumida con el rechazo de la transfusión vital, que, por lo demás, parece del mismo modo respetable desde una perspectiva ética, si responde a valoraciones personales libremente enraizadas en la conciencia del individuo». ${ }^{12}$

11 R. Navarro-Valls y J. Martínez-Torrón, Las objeciones [...], op. cit., p. 140.

12 C. M. Romeo Casabona, «¿Límites [...]», op. cit., p. 348. 
El Tribunal Constitucional español ha sostenido un criterio contrario a la tesis expuesta anteriormente - según el cual tratándose de adultos capaces la regla general es el respeto a su voluntad objetora-, pues ha considerado legítima la imposición de una transfusión al adulto objetor. El caso trata de una mujer testigo de Jehová a la que, luego de una intervención quirúrgica, resultó necesario realizarle una transfusión de sangre. Ante la negativa tanto de ella como de su esposo, de la misma confesión, al mencionado tratamiento, se requirió mandato judicial, que se otorgó y la transfusión fue impuesta a la paciente. Posteriormente, se formuló querella promoviendo el antejuicio necesario para exigir responsabilidad al Juez, por estimar que había cometido un delito contra la libertad religiosa tipificado en el Art. $205^{\circ}$ del Código Penal vigente en aquel momento. El Tribunal Supremo eximió de responsabilidad al Juez. Llegado el asunto al Tribunal Constitucional, este dijo, por Auto de 20 de junio de 1984:

"(Existe) una autorización legítima derivada de los arts. $3^{\circ}$ y $5^{\circ}$ de la Ley de Orgánica de Libertad Religiosa [...], para la actuación judicial, ya que el derecho de libertad religiosa garantizado por el artículo 16.1 de la Constitución tiene como límite la salud de las personas, según dicho Art. $3^{\circ}$, y en pro de ella actuó el Magistrado-Juez, otorgando autorización para las transfusiones sanguíneas [...]».

La doctrina del Tribunal Constitucional parece aquí situar la objeción de conciencia del adulto capaz en un caso de conflicto entre el derecho de libertad religiosa y el derecho a la vida o a la protección de la salud.

No obstante, puede encontrarse lo que sería un cambio de criterio aunque parece que no definitivo, según veremos más adelante- hacia tesis como las de Hervada, Navarro-Valls y Martínez-Torrón. Ello puede advertirse en dos sentencias de 1990 del Tribunal Constitucional, relativas a casos de huelga de hambre emprendidas por miembros del grupo terrorista GRAPO internados en prisión. En éstas se afirmó que, en circunstancias ordinarias, la imposición obligatoria de una terapia podría ser considerada como una violación de los derechos constitucionales del paciente cuando ha rehusado voluntariamente el tratamiento y aceptado el consiguiente riesgo de muerte, suponiendo que él sea el único perjudicado con su decisión. ${ }^{13}$ Este criterio bien podría ser aplicable a los casos de

13 Esto nos hace recordar al criterio de la jurisprudencia norteamericana para admitir 
objeción a tratamientos médicos por razones de conciencia y abriría el camino al reconocimiento de esta objeción en el ámbito jurisprudencial. Ha dicho el Tribunal Constitucional:

"una cosa es la decisión de quien asume el riesgo de morir en un acto de voluntad que solo a él afecta, en cuyo caso podría sostenerse la ilicitud de la asistencia médica obligatoria o de cualquier otro impedimento a la realización de esa voluntad, y cosa bien distinta es la decisión de quienes, hallándose en el seno de una relación especial penitenciaria, arriesgan su vida con el fin de conseguir que la Administración deje de ejercer o ejerza de distinta forma potestades que le confiere el ordenamiento jurídico [...]n. ${ }^{14}$ (Las cursivas son nuestras).

En una sentencia posterior, y dejando clara la aplicación de este criterio a la objeción de conciencia en los tratamientos médicos por motivos religiosos, el Tribunal Constitucional ha sostenido:

«la libertad religiosa, entendida como un derecho subjetivo de carácter fundamental, se concreta en el reconocimiento de un ámbito de libertad y de una esfera de agere licere del individuo, es decir, reconoce el derecho de los ciudadanos a actuar en este campo con plena inmunidad de coacción del Estado y de cualquiera grupos sociales [...] una asistencia médica coactiva constituiría una limitación vulneradora del derecho fundamental, a no ser que tuviera justificación constitucional». ${ }^{15}$ (Las cursivas son nuestras).

El Tribunal Superior de Justicia de Madrid, en su auto de 23 de diciembre de 1992, parece incorporar la doctrina del Tribunal Constitucio-

la objeción de conciencia a los tratamientos médicos del adulto sin hijos o personas que dependan de él.

14 STC 120/1990, de 27 de junio, FJ 7; similar criterio en STC 137/1990, de 19 de julio, FJ 5.

15 STC 166/1996, de 28 de octubre, FJ $2^{\circ}$. En esta sentencia el Tribunal Constitucional deniega un recurso de amparo por entender que no vulnera la libertad religiosa ni otros derechos fundamentales del actor (testigo de Jehová), la denegatoria judicial de reintegro de gastos médicos ocasionados por su tratamiento en una clínica privada, a la que acudió al no serle garantizado por los facultativos de la Seguridad Social un tratamiento que, adecuado a sus creencias religiosas, excluyera en todo caso la transfusión de sangre en la intervención quirúrgica que se le había de practicar. 
nal sentada en las sentencias del caso GRAPO. También está presente aquí la idea de la ausencia de voluntad suicida en el adulto objetor. El auto resuelve un recurso contra una decisión judicial que permitía la administración de hemoterapia a una enferma de cáncer incurable, perteneciente a los testigos de Jehová, con el argumento siguiente:

"Tampoco comparte la Sala la tesis, rechazada igualmente por el Ministerio Fiscal, de que el Juez tenga que autorizar forzosamente la transfusión para no incurrir en el delito de omisión del deber de socorro previsto y penado en el Art. $489^{\circ}$ del Código Penal. Si la paciente es mayor de edad, y adopta su decisión libremente, si no se trata de un menor, ni de un incapacitado, el Juez no tiene obligación ineludible de conceder autorización para realizar transfusiones, que entrañan un evidente riesgo y que admiten métodos y soluciones alternativas. Desde luego no concurre un estado de necesidad, ni se trata de un auxilio omisivo al suicidio, ya que los Testigo de Jehová no quieren la muerte sino vivir, aunque no a toda costa y a cualquier precio, ni conculcando sus creencias, por lo que su actitud no puede ser calificada de suicida, ni desde la perspectiva sicológica ni desde una perspectiva jurídica." ${ }^{16}$

Pero estas consideraciones judiciales han sido utilizadas hasta ahora solo como instrumento puramente discursivo, sin que hayan servido para evitar o condenar la hemotransfusión a un objetor de conciencia. Según comenta Romeo Casabona, el criterio de respetar la decisión del testigo de Jehová objetor de la hemotransfusión no se ha impuesto por ahora en España. Lo más frecuente es que ante situaciones de peligro vital originado por el rechazo de la transfusión de hemoderivados, cuando además ésta aparentemente no admite alternativas de tratamiento eficaz, los médicos acudan al Juez para que indique cuál es el comportamiento que han de seguir conforme a Derecho, y que aquel ordene la realización de las transfusiones necesarias médicamente, incluso con el apoyo de la fuerza pública, si fuera preciso. En algunos casos (probablemente muchos menos de los que han dado lugar a una transfusión vital coactiva) el paciente o sus familiares han planteado una querella contra el Juez que autorizó u

16 Esta resolución ha sido reproducida parcialmente en: Actualidad Jurídica Aranzadi, $\mathrm{N}^{\circ} 86,1993$, pp. 9-10. 
ordenó la transfusión, procesamiento que ha sido rechazado de forma constante por los Tribunales de Justicia. ${ }^{17}$

\section{Padres objetores de conciencia}

Hemos visto que, bajo ciertas circunstancias, puede respetarse la voluntad de un adulto que objeta un tratamiento médico aun a riesgo de su vida. Pero para que la opción libre que lesiona la salud merezca tutela jurídica, debe tratarse de la salud propia y no la ajena. Esto lleva a que no pueda extenderse la tutela de la libertad religiosa cuando la salud ajena perjudicada es la de un incapaz o un menor sujeto a patria potestad (por ejemplo, un padre testigo de Jehová que no autoriza una transfusión de sangre para su hijo menor de edad). En estos casos, los poderes públicos deberían suplantar, en virtud del orden público y la protección de los derechos de los demás, la autoridad paterna y adoptar las medidas necesarias para la protección de la vida o la salud amenazada. ${ }^{18}$ Así, en Estados Unidos, en las decisiones del Tribunal Supremo referidas a tratamientos a menores contra la voluntad de sus padres, se repite incansablemente, según destaca Palomino, el siguiente argumento: «los padres pueden ser libres de hacerse mártires a sí mismos. Pero de esto no se sigue que sean libres, en idénticas circunstancias, para hacer mártires a sus hijos hasta que estos alcancen la edad de la discreción, en la cual ellos pueden realizar esa elección por sí mismos». ${ }^{19}$

Entonces, si, conforme hemos visto, una situación de urgencia exime de recabar el consentimiento informado del paciente, en casos urgentes los médicos están habilitados a intervenir al menor pese a la negativa paterna. En situaciones no urgentes, el consentimiento negado por el titular de la patria potestad será dado por el Juez, en defensa del interés del menor (su vida y salud), que, en virtud del orden público, suplanta la autoridad paterna y adopta las medidas necesarias para la tutela de la vida o la salud del niño. ${ }^{20} \mathrm{El}$ argumento suele ser el mismo: la patria potestad no

17 C. M. Romeo Casabona, "¿Limites [...]», op. cit., p. 351.

18 Cfr. R. Navarro-Valls y J. Martínez-Torrón, Las objeciones [...], op. cit., p. 129.

19 R. Palomino, Las objeciones [...], op. cit, p. 311.

$20 \mathrm{Z}$. Combalía, «La salud como límite al derecho de libertad religiosa», en: Humana Iura $N^{\circ} 3,1993$, p. 77. También, G. Dalla Torre, Bioetica e diritto, Torino, 1993, p. 89; 
es un poder absoluto y debe ceder en caso de riesgo de derechos fundamentales, como la vida de las personas.

Es evidente que la intervención judicial debe ser considerada una solución extrema, a la que recurrir solo cuando sea imposible lograr un acuerdo entre el padre y el médico. En todo caso, las motivaciones que determinan que los padres rechacen el tratamiento para sus hijos, requieren siempre ser exploradas con gran atención, sea por el médico, sea por el Juez. Si se analiza superficialmente la situación, solo con el afán de ir contra el «mal padre», se corre el riesgo de hacer más infeliz la suerte del menor. $^{21}$

No cabe descartar que como primera medida se suministre a los pacientes cuyos padres objetan las hemotransfusiones, tratamientos y procedimientos alternativos mientras sean efectivos y no corra grave riesgo la vida del enfermo. ${ }^{22}$ Pero no siendo posible esto, se admite que una negativa al tratamiento del hijo menor por razón de las creencias religiosas, constituiría un ejercicio incorrecto o abusivo de la patria potestad, debiendo actuar entonces el médico en defensa de la vida de su paciente, bien interviniendo directamente, si se encuentra en una situación urgente y de riesgo vital, o acudiendo al Juez, si se cuenta con tiempo suficiente para solicitar tal consulta. La autoridad judicial, en el marco de su intervención obligatoria para proteger los intereses del menor, avalaría (tanto antes como después de la transfusión sino fuera posible esperar) la intervención del médico como conforme a derecho. ${ }^{23}$

Gracia plantea confrontar dos casos: el testigo de Jehová adulto que decide sobre su propia vida, y el padre de un niño menor de edad que decide sobre la vida de este. Cuando no permitimos al adulto que arries-

y F. Rivero Hernández, "Intervenciones corporales obligatorias y tratamientos sanitarios obligatorios», en: Ministerio de Sanidad y Consumo - Consejo General del Poder Judicial, Internamientos involuntarios, intervenciones corporales y tratamientos sanitarios obligatorios, Madrid, 2000, p. 215.

21 A. Santosuosso (Dir.), Il consenso informato. Tra giustificazione per il medico e diritto del paziente, Milano, 1996, p. 144.

22 L. Álvarez Prieto, «La objeción de conciencia a las transfusiones sanguíneas (Dos sentencias contradictorias) », en: Anuario de Derecho Eclesiástico del Estado XVI (2000), p. 618.

23 C. M. Romeo Casabona, “Limites [...]», op. cit., p. 330. En similar sentido J. C. Armenteros Chaparro, Objeción de conciencia a los tratamientos médicos. La cuestión de la patria potestad, Madrid, 1997, p. 78. 
gue su vida por defender sus creencias, no lo estaríamos tratando como persona y parece que transgredimos el derecho de todo ser humano a igual consideración y respeto. Con el niño sucede exactamente lo contrario: iríamos contra toda regla y contra el derecho a igual consideración y respeto si no la protegiéramos de la intención de su padre de arriesgar su vida por "sus" propias creencias religiosas. ${ }^{24}$

Lo dicho guarda coherencia con la Declaración de las Naciones Unidas sobre eliminación de toda forma de intolerancia y discriminación basada en la religión o las convicciones, de 1981, donde se proclama el derecho de los padres a «organizar la vida dentro de la familia de conformidad con su religión o sus convicciones y habida cuenta de la educación moral en que crean que debe educarse al niño", con la única reserva de "no perjudicar su salud física o mental ni su desarrollo integral [...]» (Art. 5०, párrafos $1^{\circ}$ y $\left.5^{\circ}\right)$. Aquí se tiene en cuenta claramente el límite del respeto de los derechos de terceros que tiene el ejercicio de la libertad religiosa. ${ }^{25}$

Este problema ha sido visto por la Corte Constitucional italiana a propósito de la objeción de conciencia de los padres a la vacunación de los hijos. Se trata de la Ley de 4 de febrero de 1966, No 51, sobre la obligatoriedad de la vacunación antipoliomielítica para los niños dentro del primer año de edad, vacunación que, además, constituye condición para el acceso del niño a la escuela. Para la Corte, frente a la negativa de los padres a la aplicación de vacunas, estando de por medio la tutela de la salud del menor y su derecho a la educación, el Juez puede adoptar el procedimiento idóneo para someter al niño a la vacunación, basándose en las normas del Código Civil (arts. $333^{\circ}$ y 336 ) que le autorizan a adoptar las providencias convenientes ante una conducta de los padres perjudicial a los hijos. La potestad de los padres frente al menor, dice la Corte, es reconocida en el Art. $30^{\circ}$, párrafos $1^{\circ}$ y $2^{\circ}$ de la Constitución italiana, ${ }^{26}$

24 D. Gracia, Fundamentos de bioética, Madrid, 1989, p. 584.

25 Sobre los límites del derecho de libertad religiosa, puede consultarse Z. Combalía, "Los límites del derecho de libertad religiosa", en: VV.AA., Tratado de Derecho Eclesiástico, Pamplona, 1994, pp. 469-510; y J. Calvo Álvarez, Orden público y factor religioso en la Constitución española, Pamplona, 1983.

26 Art. $30^{\circ}$, Constitución italiana:

"Es deber y derecho de los padres mantener, instruir y educar a los hijos aunque hayan nacido fuera del matrimonio.

En caso de incapacidad de los padres, la ley se ocupará del cumplimiento de tales cometidos [...]". 
no como libertad personal de estos, sino como derecho-deber que encuentra en el interés del hijo su función y su límite. La Constitución ha revertido la condición que sometía a los hijos a un poder absoluto e incontrolado, afirmando el derecho del menor a un pleno desarrollo de su personalidad y coligando funcionalmente a tal interés los deberes inherentes, primero aún que los derechos, al ejercicio de la patria potestad. Es precisamente esto el fundamento constitucional de los citados artículos del Código Civil italiano que autorizan al Juez a intervenir cuando los padres descuidan sus obligaciones, perjudicando derechos fundamentales del menor como la salud (la vida) o la instrucción. ${ }^{27}$

Similar criterio es seguido por el Tribunal Supremo español en su sentencia de 26 de setiembre de 1978. El caso surgía por la negativa de un matrimonio, ambos testigos de Jehová, a que se realizara una transfusión de sangre a su hija menor de edad, cuya vida peligraba si no se procedía urgentemente a la aplicación de dicho tratamiento. El Juez requerido por el equipo médico ordenó que se practicara la transfusión, contra la voluntad de los padres. Interpuesta por ambos querella criminal contra el Juez, el Tribunal Supremo la repelió, aduciendo que el «derecho de patria potestad no puede extenderse a la menor que se encuentra en peligro de muerte». ${ }^{28}$

Por tanto, si los padres no consienten una actuación médica que sea necesaria para preservar la salud del menor, el Juez podrá suplir tal autorización, por cuanto actuará en beneficio del menor, bien en aplicación del Art. 154.II del Código Civil (CC) —cuando señala que la patria potestad se ejercerá siempre en beneficio de los hijos-, bien del Art. 158.3 CC que faculta al Juez a dictar las disposiciones que considere oportunas a fin de apartar al menor de un peligro o de evitarle perjuicios.

El Defensor del Pueblo también se ha pronunciado al respecto, afirmando que debe «sostenerse la inexistencia en nuestro ordenamiento de

27 Sentenza 16-27 marzo 1992, N 132, en: S. Domianello, Giurisprudenza Costituzionale e fattore religioso. Le pronunzie della Corte Costituzionale in materia ecclesiastica, Milano, 1999, pp. 552-554. Es también en Italia donde encontramos que el Art. 32 ${ }^{\circ}$ del nuevo Código de Deontología Médica prescribe: "cuando el paciente es un menor o enfermo mental, el consentimiento informado debe ser prestado por el representante legal", añadiendo: «en caso de oposición a tratamientos necesarios o indiferibles a favor de menores o incapaces por parte del representante legal, el médico está obligado a informar a la autoridad judicial».

28 R. Navarro-Valls y J. Martínez-Torrón, Las objeciones [...], op. cit., p. 138. 
derecho alguno que permita a los padres disponer de la vida de los hijos sometidos a su patria potestad. La función parental en modo alguno permite llegar a ese extremo [...] cuando los padres, tutores, parientes o allegados se opongan a un tratamiento médico no urgente a un menor de edad, se debería elevar el conflicto al Ministerio Fiscal para que este pudiera solicitar del juez las medidas necesarias para proteger el superior interés del menor que inspira [...] nuestro ordenamiento jurídico interno, así como los convenios sobre la materia suscritos por nuestro paísm. ${ }^{29}$

¿Y qué ocurriría si existen discrepancias entre los titulares de la patria potestad sobre la intervención médica, en el sentido que uno esté a favor de ésta y el otro la rechace? Aquí habrá también que distinguir entre situaciones urgentes y de no urgencia.

Como venimos diciendo, una situación de urgencia faculta al médico a intervenir directamente, sin que tenga que contar con autorización paterna o judicial. Asimismo, en opinión de Herranz, el Art. $113^{\circ}$ del Código español de Ética y Deontología Médica habilita al médico a tratar sin consentimiento en casos de discrepancia entre padres, pues se habrá presentado un desacuerdo irreductible entre quienes han de decidir que haría imposible obtener el consentimiento de estos. ${ }^{30}$

Fuera de los supuestos de urgencia, este problema tendría que ser resuelto conforme a las normas del CC para los casos de desacuerdo entre los titulares de la patria potestad. Conforme al Art. 156.II CC, cualquiera de los dos progenitores podrá acudir al Juez, quien, después de oír a ambos y al hijo si tuviera suficiente juicio y, en todo caso, si fuera mayor de doce años, atribuirá la facultad de decidir al padre o a la madre. ${ }^{31}$ Pero si los padres no recurren al Juez, los médicos podrían instar la intervención del Ministerio Fiscal, que podrá pedir al Juez que dicte las disposiciones oportunas a fin de apartar al menor de un peligro o de evitarle perjuicios (Art. 158.3 CC).

29 Recomendación $N^{\circ} 58 / 1994$, de 20 de setiembre, sobre relevancia del consentimiento paterno en los tratamientos médicos a menores, en: BOCG, Cortes Generales, $\mathrm{V}$ Legislatura, Serie A, No 50, p. 9; también, Recomendación N59/1994, de 20 de septiembre, sobre fallecimiento de menores como consecuencia de la negativa de los padres a suministrarles el tratamiento previsto por los médicos, en: BOCG, Cortes Generales, $\mathrm{V}$ Legislatura, Serie A, No 50, p. 8.

30 G. Herranz, Comentarios al Código de Ética y Deontología Médica, Pamplona, 1992, p. 57.

31 Cfr. J. C. Armenteros Chaparro, Objeción [...], op. cit., p. 81. 


\section{Menor maduro}

Habiendo revisado ya los problemas en torno a la objeción de conciencia a tratamientos médicos en el adulto, podemos enfrentarnos, con los elementos de juicio vistos hasta aquí, al caso en que el objetor de conciencia sea un niño, cuyo solo planteamiento muestra la dificultad del tema.

Las razones de esta especial complejidad - las cuales son igualmente predicables para cualquier conflicto que atañe a menores- estarían en que el niño está sometido a la patria potestad, por la cual sus padres deben prestar asistencia de todo orden a sus hijos durante su minoría de edad, como señala el Art. 39.3 de la Constitución española (CE), y ésta debe ejercerse siempre en beneficio de los hijos (Art. 154\%. II CC). Y porque, además, por tratarse de un niño, entrará en juego el llamado interés superior del menor, ese concepto jurídico indeterminado que exigirá que, en un caso concreto, la instancia a la que le corresponda una decisión que incida sobre el menor (los padres, el juez o la administración), deberá actuar siempre según lo más favorable para el niño. ${ }^{32}$

Naturalmente el menor, por ser persona, es titular del derecho de libertad religiosa (Art. 16 $6^{\circ} \mathrm{CE}$ ). Así lo ha reconocido expresamente la Convención de la ONU sobre Derechos del Niño de 1989 (Art. 14.1) y la Ley Orgánica $N^{\circ} 1 / 1996$, de 15 de enero, de Protección Jurídica del Menor (LOPJM), en su Art. 6.1. Pero tanto la Convención como la LOPJM realizan algo que es ya una clara tendencia en el Derecho: el reconocimiento pleno de la titularidad de derechos en los menores de edad y, al mismo tiempo, el reconocimiento de una capacidad progresiva para ejercerlos, en función de su grado de madurez. Así, estas normas dirán que el menor puede ejercer el derecho de libertad religiosa y que corresponde a sus padres, como guías o directores, cooperar para que el niño ejerza esta libertad conforme a la evolución de sus facultades, es decir a su grado de madurez, de modo que contribuya a su desarrollo integral (Art. 14.2 de la Convención y Art. 6.3 de la LOPJM).

Aceptada, entonces, la capacidad del menor de ejercer el derecho de libertad religiosa conforme a su grado de madurez, surge inmediatamente una pregunta: ¿a partir de cuándo puede entenderse que el niño tiene la madurez suficiente como para ejercer el derecho de libertad religiosa?

32 Cfr. por todos, F. Rivero Hernández, El interés del menor, Madrid, 2000, pp. 87 190. 
El Derecho comparado nos muestra ejemplos muy interesantes de ejercicio de la libertad religiosa del menor. En Italia, conforme al Art. $1^{\circ} \mathrm{de}$ la Ley de 18 junio de 1986, № 281, se da al menor, por lo general de catorce años, el derecho de elegir si asiste o no a la enseñanza de la religión, en la escuela secundaria superior. ${ }^{33}$

La ley alemana sobre educación de los niños (Gesetz über die religiöse Kindererziehung), de 15 de julio de 1921, señala que a partir de los catorce años de edad, toda persona tiene derecho a elegir libremente su religión. En un efecto previo de esa capacidad, con el cumplimiento de los doce años de edad, el niño no puede ser obligado a recibir una enseñanza religiosa distinta a la que venía recibiendo. ${ }^{34}$ Norma similar rige en Austria, donde si el niño ha alcanzado los doce años de edad es necesario que quienes ejerzan la patria potestad obtengan su consentimiento para cambiar su educación religiosa. Una vez cumplidos los catorce años, el menor puede libremente elegir una confesión religiosa. ${ }^{35}$

En Portugal, el Art. $1886^{\circ}$ del Código Civil prescribe que pertenece a los padres decidir sobre la educación religiosa de los hijos menores de dieciséis años. Y en la misma línea, la ley portuguesa de libertad religiosa (No 16/2001 de 22 de junio) señala que los menores a partir de los dieciséis años tienen derecho a ejercer por sí mismos su libertad religiosa (Art. 11.2).

El Código Civil suizo dispone, en su Art. 3030, que la persona que ha cumplido dieciséis años de edad puede escoger libremente su confesión religiosa. ${ }^{36}$

33 Se trata de una fórmula no exenta de críticas, pues según apunta D. Llamazares Fernández, citando a Finocchiaro, uesta solución podría entrar en contradicción con el artículo 30.1 de la Constitución y con el derecho que allí se reconoce a los padres a educar a sus hijos, dado que los alumnos de primer curso en esos centros no pasan de los catorce años, edad en la que [...] es cuestionable que se tenga la madurez requerida para este tipo de decisión» (Derecho Eclesiástico del Estado. Derecho de la libertad de conciencia, Madrid, 1991, p. 389).

$34 \mathrm{Cfr}$. A. Hollerbach, "La enseñanza de la religión como asignatura ordinaria en las escuelas públicas y privadas de la República Federal de Alemania», en: C. Corral y J. Listl (Ed.), "Constitución y Acuerdos Iglesia-Estado. Actas del II Simposio Hispano-Alemán", Madrid, 1988, p. 194.

35 Ley federal sobre educación religiosa de los hijos (BGBI No 155/1985). Cfr. R. Potz, "Estado e Iglesia en Austria», en: G. Robbers (Ed.), Estado e Iglesia en la Unión Europea, Madrid, 1996, p. 258.

36 Podemos mencionar también el caso de Dinamarca (donde la enseñanza religiosa es el cristianismo evangélico luterano). A solicitud de los padres, el niño puede quedar exento 
Entrando al Derecho español, es obvio que quien ha alcanzado la mayoría de edad puede ejercer con plena autonomía todos sus derechos fundamentales. Sin embargo, también es evidente que la situación de un ser humano no cambia tan radicalmente al llegar a la edad adulta, como para que pueda entenderse que antes de arribar a ella es en todo caso incapaz de ejercitar sus derechos fundamentales. En aras de la seguridad jurídica, el Derecho señala una edad (dieciocho años en la generalidad de los ordenamientos), que indique, de manera objetiva, la llegada a la adultez en todos los casos, salvo, por supuesto, declaración judicial en contrario.

La salida progresiva de la menor edad y la entrada en la edad adulta, es una realidad advertida por el Derecho. Prueba de ello es que la legislación contemple casos en los que el menor puede ejercer por sí mismo sus derechos o actuar como un adulto, en vista de que ciertas circunstancias (una determinada edad, la conducta del menor) resultan indicativas o presuntivas de su madurez, antes de haber alcanzado la mayor edad. Así, por citar algunos casos:

- El derecho civil aragonés señala, en el Art. 5.1 de su Compilación, que el menor de edad, cumplidos los catorce años, aunque no esté emancipado, puede, en términos generales, celebrar por sí toda clase de actos y contratos, con asistencia, en su caso, de uno cualquiera de sus padres. ${ }^{37}$

- En el Derecho civil común, el menor puede contraer matrimonio, con dispensa judicial, a partir de los catorce años (Art. 48.II CC). Si se casa, quedará emancipado como consecuencia directa del matrimonio (arts. 314.2 y $316 \mid \mathrm{CC})$.

- Conforme al Art. $319^{\circ} \mathrm{CC}$, el niño puede recibir la emancipación por vida independiente si cuenta con, por lo menos, dieciséis años y si se constata fácticamente su capacidad natural para gestionar sus propios asuntos e intereses, que demuestre su efectiva autonomía económica.

de tal enseñanza, pero si ha alcanzado los quince años, es necesario su consentimiento para la exención (I. Dübeck, «Estado e Iglesia en Dinamarca», en: R. Potz, Estado e Iglesia en Austria, en: G. Robbers [Ed.], «Estado e Iglesia en la Unión Europea», Madrid, 1996, p. 49).

37 Cfr. F. Sancho Rebullida - P. De Pablo Contreras, «De la capacidad de las personas por razón de la edad", en: J. L. Lacruz Berdejo (Dir.), Comentarios a la compilación del Derecho Civil de Aragón, I, Zaragoza, 1988, p. 308. 
- Diversas disposiciones del CC prevén que el menor sea oído antes de adoptar decisiones que le afecten, si tuviera suficiente juicio y, en todo caso, si fuera mayor de doce años. ${ }^{38}$

- El Art. 162.II.1 CC excluye de la representación legal los actos relativos a derechos de la personalidad u otros que el hijo, de acuerdo con las leyes o con sus condiciones de madurez, pueda realizar por sí mismo.

Por lo visto, parece reconocerse que a partir de un determinado momento anterior a la mayoría edad - los doce, catorce o dieciséis ańos-, puede presumirse que el menor ha alcanzado capacidad natural ("suficiente juicion, suele decir la legislación) como para otorgarle capacidad de obrar en ciertas situaciones concretas, sobre todo relacionadas con aquellos asuntos que más directamente afecten a su esfera personal, a sus derechos humanos, como los derechos de la personalidad.

En el ordenamiento español, si bien está muy claro el reconocimiento de la libertad religiosa del menor y su posibilidad de ejercer este derecho -lo cual ha sido además reafirmado por el Tribunal Constitucional en sus Sentencias 141/2000 de 29 de mayo ${ }^{39}$ y, más recientemente, 154/ 2002 de 18 de julio que comentamos más adelante-, no se reconoce una edad concreta en la que el menor pueda ejercer, por sí mismo, su derecho de libertad religiosa. Sin embargo, atendiendo a la revisión legislativa efectuada, podemos plantear como una edad de referencia para presumir tal madurez en materia de libertad religiosa - con cargo, por supuesto, a su análisis caso por caso-, los catorce años, con más claridad a medida que el menor está más próximo a alcanzar la mayoría de edad.

Pero no hay que perder de vista que, a falta de ley expresa, el dato de la edad es solo referencial. El juicio acerca del discernimiento o madurez del menor, deberá hacerse en cada caso concreto (siempre en cada caso concreto), en donde, además de los datos psicológicos relacionados con su desarrollo personal (eminentemente, de raciocinio y autocontrol de su voluntad), deberá tenerse en cuenta si hay una mínima racionalidad de la opinión u opción del menor: es decir, que el deseo por él expresado sea congruente con los fines contemplados por este, que las metas marcadas o deseadas por el menor en cuestión sean razonablemente alcanzables y realizables en el marco de la realidad vital y social en que se desenvuelve. ${ }^{40}$

38 Cfr. por ejemplo, arts. $154 . I I, 156^{\circ}, 92 . I I, 173.2,177^{\circ}$ y $231^{\circ} \mathrm{CC}$.

39 FJ 5.

40 F. Rivero Hernández, El interés [...], op. cit., p. 221. 
Al ejercer el menor su derecho de libertad religiosa, sus opciones religiosas podrían ser, inclusive, distintas a las de sus padres. Pero, siendo los padres, en el desempeño de la patria potestad, los primeros responsables de velar por el niño y por la prevalencia de su superior interés, les corresponde, en primer término, atender que el menor ejerza tal derecho dentro de los límites del ordenamiento jurídico, por lo que no deben quedar al margen de las decisiones de sus hijos en esta materia. En consecuencia, no se propone habilitar al menor a actuar sin conocimiento de sus padres o sin que se deba tomar en cuenta, eventualmente en sede judicial, la oposición razonable de éstos.

\section{La objeción de conciencia del menor}

Antes de entrar en el tema de este apartado, pensemos qué ocurriría si un menor con suficiente grado de madurez, disintiendo de sus padres, conviene en que se le practique un tratamiento médico que le resulta vital, como una hemotransfusión. Podemos aplicar aquí el criterio de Rivero Hernández, para quien en caso el menor tenga una edad (quizá entre quince o diecisiete años) y una capacidad de discernimiento y juicio suficiente para entender la gravedad y alcance de la autorización o consentimiento que el médico le pide, tras la negativa de los padres, sí podrá dar él mismo tal consentimiento para la intervención médica, de conformidad con el Art. 162.II.1 CC, que excluye de la representación paterna «los actos relativos a derechos de la personalidad $u$ otros que el hijo, de acuerdo con las Leyes y con sus condiciones de madurez, pueda realizar por sí mismo». Podría sostenerse que una decisión como ésta cae dentro del ejercicio de derechos de la personalidad. ${ }^{41}$

Veamos ahora qué ocurre cuando el objetor de conciencia es el menor. Quienes postulan que cabe respetar la objeción de conciencia de este, senalan como requisito, obviamente, su suficiente madurez. Así, para

$41 \mathrm{Idem}$, Intervenciones [...], op. cit., p. 216. Sobre los derechos de la personalidad puede consultarse J. L. Lacruz Berdejo, Elementos de Derecho Civil. Parte General, I.2, Madrid 1999, pp. 50-113, desde una perspectiva amplia. Una visión más restrictiva es la del profesor Martínez de Aguirre, en: C. Martínez de Aguirre, P. De Pablo Contreras, M. A. Pérez Álvarez y M. Parra Lucán, Curso de Derecho Civil. Derecho Privado. Derecho de la Persona, I, Madrid, 1998, pp. 455-484. 
Hervada un menor con uso de razón y capaz de juicios morales proporcionados a la decisión necesaria para el caso, si tiene las mismas convicciones morales que sus representantes legales y la aplicación de la terapéutica lesiona su conciencia, ésta no debe aplicársele. ${ }^{42}$

Por el contrario, Romeo Casabona ${ }^{43}$ no cree admisible la objeción de conciencia del menor aun cuando tenga suficiente juicio. Comentando el caso de Huesca, que reseñamos en el siguiente apartado, dirá que si bien no cabe duda que a los trece años —edad del menor en dicho casopueden ejercitarse con plena capacidad numerosas manifestaciones del derecho a la libertad religiosa (p. ej., practicar actos de culto, acudir a los lugares establecidos para ello, etc.), es más que dudoso que esto pueda llevarse a sus extremas consecuencias hasta el punto de poner en peligro la propia vida o conducir a su pérdida. El que un menor cuente con juicio suficiente es, no obstante, condición suficiente para que se proceda a informarle y que sea oído en todo caso, como apunta la LOPJM (Art. 9\%).

Para el mencionado autor, esta es una forma de concretar el principio general de la LOPJM de que en la aplicación de esta ley primará el interés superior de los menores sobre cualquier otro interés legítimo que pudiera concurrir, pues su interés superior ha de ser, entre otros, el de preservar su vida para que pueda ejercer con plenitud todos los demás derechos cuando alcance la mayoría de edad. Solo a partir de entonces se le reconoce el ejercicio de todos los derechos civiles y políticos, sean o no fundamentales. Si, por ejemplo, el menor no tiene el derecho al voto, no debería resultar extraño que tampoco se le reconozca la libertad de decidir sobre su propia vida o, dicho de otro modo, de adoptar decisiones en sí mismas no disvaliosas, pero que pueden llegar a tener como efecto inseparable la propia muerte, aun cuando haya sido asumida. Además, hay que tener en cuenta el riesgo de manipulación del menor, incluso por sus propios representantes legales. ${ }^{44}$

42 J. Hervada, Libertad de conciencia [...], op. cit., p. 50.

43 C. M. Romeo Casabona, "¿Límites [...]", op. cit., p. 338 . De similar opinión es B. Navas Renedo, Tratamiento jurídico de las sectas. Análisis comparativo de la situación en España y Francia, Granada, 2001, p. 206.

44 Este riesgo de manipulación se toma en cuenta en la LOPJM (Art. $4^{\circ}$ ) para reforzar la protección de los derechos al honor, la intimidad y propia imagen del menor, según informa la Exposición de Motivos esta ley. 
Una vez más es necesario distinguir entre situaciones urgentes y los que no lo son. La urgencia, como ya sabemos, faculta a los médicos a intervenir, no obstante la objeción del menor o de sus padres. En un caso no urgente, solo si la ley exigiera contar con el consentimiento del menor maduro para la práctica médica, sería necesario acudir al Juez. Sin ese mandato legal, bastará con el consentimiento de los padres, pese a la objeción del menor.

En nuestra opinión, hacer depender de un niño el consentimiento para un tratamiento médico que puede resultarle vital, es una excepción a su falta de capacidad de obrar, por lo que debería venir expresamente prevista en la ley, con el señalamiento de una edad concreta a partir de la cual recabar tal consentimiento. ${ }^{45}$ Habilitar al menor exigiendo genéricamente "madurez suficiente", no termina de resolver el problema, pudiendo prestarse a interpretaciones arbitrarias, contradictorias o dispares.

A partir de la mayoría de edad se presume la plena capacidad de obrar de la persona; cualquier excepción a esto debería estar prevista en la ley, pues la regla general será que el menor esté bajo la potestad de sus padres y se debe proceder siempre conforme a su mejor interés, el cual implica, obviamente, proteger sus derechos fundamentales, como su derecho a la vida.

Por esta razón, si desde la ética médica se recomienda obtener el consentimiento informado del menor maduro en ciertos supuestos, mientras no haya una norma que lo señale como obligatorio, no recabar tal aquiescencia solo podrá dar lugar a un problema ético pero, obviamente, no a una vulneración de la ley.

Una opinión discrepante es la de Galán Cortés, para quien cuando se trate de menores que reúnan condiciones de madurez suficiente, deben ser ellos mismos quienes autoricen la intervención médica, en virtud del

45 Como ocurre, por ejemplo, en las Comunidades Autónomas de Aragón y Cataluña. En la primera, el Art. 32.3 de la Ley No12/2001, de 2 de julio, prescribe que cuando fuera necesario someter a un menor a pruebas médicas o diagnósticas que requieran consentimiento expreso para su realización, si el niño tiene más de doce años, será necesario su consentimiento junto con el de sus padres, pero la ley puntualiza que, en todo caso, primará el derecho a la vida del menor y, frente a la negativa de las personas antes mencionadas a que se realicen las pruebas o tratamiento, deberá resolver la autoridad judicial de acuerdo a las circunstancias. En Cataluña, la Ley No 21/2000, de 21 de diciembre, señala, en su Art. 7.2.d, que en los tratamientos médicos a menores será necesario el consentimiento de éstos si cuentan con más de dieciséis años. 
Art. 162.II.1 CC, ${ }^{46}$ que exceptúa de la representación legal los actos relativos a derechos de la personalidad u otros que el hijo, de acuerdo con las leyes o con sus condiciones de madurez, pueda realizar por sí mismo.

Pero en lo relativo a los derechos de la personalidad, habrá que atenerse, en primer lugar, a las reglas propias (leyes especiales) que priman sobre el mencionado artículo cuando exista un desarrollo concreto. ${ }^{47}$ En cualquier caso, no queda excluida la intervención de los guardadores, pues éstos tienen el deber de velar por el menor (Art. $154^{\circ} \mathrm{CC}$ ). ${ }^{48}$ Por lo demás, la actuación del representante legal en los derechos de la personalidad queda morigerada, pero no descartada o excluida, pues su actuación respecto a la esfera personal del menor puede venir autorizada (y aún exigida) en cumplimiento de su función de velar por el niño, ${ }^{49}$ aun cuando tenga suficiente madurez.

Debe tenerse en cuenta que el Art. 162.II.1 CC no supone que el menor realizará por sí solo todos los actos relativos a derechos de la personalidad, ni siquiera teniendo discernimiento suficiente. Actuará por sí solo en el matrimonio (acto personalísimo), por ejemplo, pero, ciertamente, no así para celebrar contratos que, además de vincularlo, afecten a sus derechos de la personalidad; ni para el ejercicio judicial de las acciones que le correspondan por violación de sus derechos. Cabrá siempre exigir para una actuación del menor susceptible de afectar irreparablemente a sus derechos de la personalidad, el asentimiento de sus guardadores o la intervención de autoridad externa a la familia. ${ }^{50}$

La legislación nos alcanza un ejemplo para lo que sostenemos: que la protección del menor, aun cuando ejerza sus derechos de la personalidad, demanda mecanismos de control, como los padres o una autoridad externa. Así, si bien el Art. $3^{\circ}$ de la Ley Orgánica oo 1/1982, de 5 de mayo, de Protección civil del derecho al honor, la intimidad personal y familiar

46 J. C. Galán Cortés, Responsabilidad médica y consentimiento informado, Madrid, 2001, p. 78.

$47 \mathrm{M}$. C. Gete-Alonso, La nueva normativa en materia de capacidad de obrar de la persona, Madrid, 1992, p. 52.

48 L. Díez Picazo y A. Gullón, Sistema de Derecho Civil, IV, Madrid, 1989, p. 292.

49 C. Martínez de Aguirre, «La protección jurídico-civil de la persona por razón de la menor edad. (Una aproximación teleológica a las instituciones de asistencia y protección de menores en nuestro Derecho civil)", en: Anuario de Derecho Civil XIV (MCMXCII), p. 1440.

50 J. L. Lacruz Berdejo, Elementos [...], op. cit., p. 127. 
y a la propia imagen, prescribe que el consentimiento para la intromisión en los mencionados derechos cuando correspondan a un menor, debe ser prestado por este si sus condiciones de madurez lo permiten, la LOPJM prohibe la difusión de datos o imágenes referidos a menores de edad en los medios de comunicación cuando sea contrario a su interés, incluso cuando conste el consentimiento del menor (Art. 4.3), caso en el cual intervendrá el Ministerio Fiscal que instará de inmediato las medidas cautelares y de protección previstas en la ley. "Con ello - continúa la Exposición de Motivos - se pretende proteger al menor, que puede ser objeto de manipulación incluso por sus propios representantes legales o grupos en que se mueve». ${ }^{51}$

Si aun una norma que regula el ejercicio de los derechos de la personalidad del menor prevé un sistema de control, mal podemos, invocando el Art. 162.II.1 CC, establecer una regla de competencia general del menor maduro para hacer depender de este el consentimiento para la práctica médica, quedando al margen la autoridad de sus padres. Insistimos en que, a falta de ley que mande lo contrario, el consentimiento necesario será el de los representantes legales y la no obtención del consentimiento del menor no impedirá la práctica médica. En cualquier caso, puede citarse el referido Art. 162.II.1 CC para recabar el consentimiento del menor maduro junto con el de sus padres, pero sin que este sea un requerimiento impuesto por la ley, sino solo el seguimiento de una recomendación ética.

Por supuesto, estamos suponiendo que la intervención médica se justifica por la necesidad o beneficio del menor, conforme a la valoración de su interés realizada por los primeros llamados a ello, sus padres, quienes tienen la obligación de velar por niño y la potestad necesaria al efecto. Un tratamiento médico que no persiga estos fines sería delictivo.

V. Criterios jurisprudenciales sobre la objeción de conciencia del menor en los tratamientos médicos

Un conocido caso de objeción de conciencia, donde el propio menor parece haberla formulado, lo encontramos en la provincia aragonesa de

51 Según la misma Exposición de Motivos, esta regulación se hace en «la necesidad de matizar" algunos derechos de los menores, "combinando, por una parte, la posibilidad de su ejercicio con la necesaria protección que, por razón de la edad, los menores merecen». 
Huesca. A un niño de trece años le fue indicado una hemotransfusión, tras sufrir una caída de su bicicleta que le produjo una hemorragia. Los padres (testigos de Jehová) se negaron a este tratamiento, por lo que los médicos recurrieron al Juez. Conseguida la autorización judicial, al momento en que se intentó transfundir al menor, este rechazó el tratamiento, reaccionando agitada y violentamente, por lo que los médicos no prosiguieron.

Luego de un periplo de los padres por otros hospitales, en busca de un tratamiento alternativo sin sangre, el menor retornó a su domicilio. Al día siguiente, y ante el deterioro de su salud, un Juez, a instancias del Ayuntamiento, ordenó el traslado del menor a un hospital. El niño finalmente falleció sin recibir a tiempo la transfusión.

\section{A. Posición de la Audiencia Provincial de Huesca}

La Fiscalía de Huesca consideró que los padres debían ser acusados de parricidio y no simplemente de omisión al deber de socorro. Sin embargo, la Audiencia Provincial de Huesca, por sentencia de 20 de noviembre de 1996, absolvió a los padres, con el argumento de que no parece exigible que éstos, tras llevar a su hijo a un centro adecuado, tengan obligatoriamente que renunciar, en contra de su conciencia, a sus convicciones religiosas para pasar a pedir o aprobar una transfusión que consideran moralmente perniciosa e inadecuada, no siendo tampoco jurídicamente exigible que los progenitores deban intentar convencer a su hijo de que se someta a la transfusión.

La Audiencia Provincial de Huesca aborda el tema de la objeción de conciencia del adulto a los tratamientos médicos, asumiendo la tesis que plantea que no estamos aquí ante un supuesto de suicidio:

«cuando se trata de personas adultas un importante sector de la doctrina tiene en cuenta que posturas como las aquí contempladas, rechazando una transfusión por motivos religiosos, aunque puedan parecer próximas al suicidio (como se vino a decir en el Auto del Tribunal Supremo de 14 de marzo de 1979), se diferencian radicalmente de este pues el paciente no quiere, ni busca, ni asume su propia muerte, sino que [...] doctrinalmente, únicamente «acepta el riesgo de muerte, desde la persecución de la vida, aunque no a toda costa y a cualquier precio", riesgo de muerte que, además, no deriva de su propia voluntad, (como sucede con el suicidio típico o en si- 
tuación de huelga de hambre), sino de un fatal accidente o de una enfermedad adquirida previamente y por causas naturales, sin intervención consciente de la voluntad del paciente quien, manifestada la enfermedad o sufridas las lesiones derivadas del accidente, se limita a rechazar, si está consciente, por convicción religiosa, una transfusión [...]" (Fd Segundo).

En cuanto a la objeción de conciencia del menor, la Sentencia se limita a plantear los problemas que se presentan entorno a ella (en concreto, el tema de la edad), sin concluir nada al respecto. Sostiene que los menores son titulares del derecho de libertad religiosa (algo que, por lo demás, no tiene mayor discusión), pero no queda claro que con ello esté afirmando que pueden ser objetores de conciencia a tratamientos médicos. Dice la sentencia:

"en el caso de menores [...] el problema, ya de por sí muy complejo, se acrecienta, haciendo preciso establecer, si es que existe realmente el derecho del paciente a la autodeterminación (pudiendo libre y eficazmente consentir, o rechazar, un tratamiento médico después de ser debidamente informado), a partir de qué momento puede el menor que conserva la conciencia decidir sobre si se le aplica o no un determinado tratamiento, si cuando deja de serlo (menor) por alcanzar la mayoría de edad, o si, por el contrario, tal decisión puede adoptarla cuando tiene suficiente juicio (cosa que en nuestro derecho se puede dar incluso antes de alcanzar los doce años, artículo $92^{\circ}$ del Código Civil), o cuando puede consentir una relación sexual (doce años para el artículo $181^{\circ}$ del vigente Código Penal), etc. Pues bien, centrándonos en el concreto caso examinado, de entrada, por disponerse así no solo en el artículo $16^{\circ}$ de la Constitución sino, también, ya específicamente, en el artículo sexto de la Ley orgánica 1/1996, de protección jurídica del menor, resulta indiscutible que los menores tienen también derecho a la libertad de ideología, conciencia y religión" (fd segundo).

\section{B. Posición del Tribunal Supremo: condición de garantes de los padres e irrelevancia del consentimiento del menor}

El Ministerio Fiscal recurrió esta decisión ante el Tribunal Supremo, que resolvió por sentencia de 27 de junio de 1997, condenando a los 
padres por el delito de homicidio, en su modalidad de comisión por omisión, con la atenuante muy calificada de obcecación, por lo que se impone la pena inferior a dos grados, que se concreta en la mínima de dos años y seis meses de prisión. Por las mismas excepcionales circunstancias de este caso, la Sala queda en "predisposición de informar favorablemente un indulto parcial, caso de que así se solicitara por los encausados".

En cuanto a la objeción de conciencia en adultos, la Sentencia del Tribunal Supremo acoge una tesis permisiva, con las limitaciones que hemos apuntado en este trabajo. ${ }^{52}$ Además, rechaza que los padres puedan objetar el tratamiento médico de su hijo:

«El adulto capaz puede enfrentar su objeción de conciencia al tratamiento médico, debiéndose respetar su decisión, salvo que con ello ponga en peligro derechos o intereses ajenos, lesione la salud pública u otros bienes que exigen especial protección. Muy distinta es la situación cuando la persona que requiere el tratamiento para salvar la vida o evitar un daño irreparable es un menor. En este caso es perfectamente legítimo y obligado ordenar que se efectúe el tratamiento al menor aunque los padres hayan expresado su oposición. El derecho a la vida y a la salud del menor no puede ceder ante la afirmación de la libertad de conciencia u objeción de los padres. Si éstos dejan morir a su hijo menor porque sus convicciones religiosas prohiben el tratamiento hospitalario o la transfusión de sangre, se genera una responsabilidad penal exigiblen.

Dice el Tribunal Supremo que la posición de garante de los padres no se ve afectada por el hecho de que el hijo, miembro de la misma confesión, también rechace la hemotransfusión. ${ }^{53}$

La referencia que el Tribunal Supremo hace de la objeción de conciencia por parte del menor a los tratamientos médicos, es para descartarla de plano, especialmente si es formulada a la edad que tenía el niño de este caso:

52 Cfr., supra, $\mathrm{N}^{\circ} 1$.

53 «La posición de garante, presente en los padres, no se ve afectada por el hecho de que el hijo, miembro de la misma confesión religiosa, también se opusiera a la transfusión de sangre». 
«Como destaca el Ministerio Fiscal, en los razonamientos de su recurso, el derecho positivo aporta expresivos ejemplos acerca de la irrelevancia del consentimiento u oposición de un niño de trece años de edad, máxime cuando, como en este caso, está en juego su propia vida».

No se plantea el Tribunal Supremo el tema de la posible madurez de una persona de trece años, ni si es que ésta podría indagarse en una edad posterior o en determinadas circunstancias. Ni qué ocurriría si fuera la ley la que mandara contar con el consentimiento del niño. Por tratarse de un menor de edad, deja toda responsabilidad en sus padres. ${ }^{54}$

\section{Posición del Tribunal Constitucional}

Llegado el asunto al Tribunal Constitucional, este ha resuelto en Sentencia 154/2002, de 18 de julio.

Esta sentencia reconoce la titularidad del derecho de libertad religiosa del menor y su capacidad de ejercer este derecho de modo conforme a la evolución de sus facultades: «El menor expresó con claridad, en ejercicio de su derecho a la libertad religiosa y de creencias, una voluntad, coincidente con la de sus padres, de exclusión de determinado tratamiento médico". 55

Un elemento importante que introduce el Tribunal Constitucional en la discusión sobre la objeción de conciencia a los tratamientos médicos, es el compromiso en ésta del derecho fundamental a la integridad física:

54 Este juicio es compartido por el Estado, que afirma, a propósito de este caso, que no puede desprotegerse «la vida de los menores hasta el punto de considerar impune la conducta de las personas responsables del cuidado del menor que, basándose en ciertas creencias de ellos mismos y/o del propio menor, no le suministran el tratamiento médico que en el caso concreto podría salvar su vida. La voluntad del menor de trece años de no someterse al tratamiento resulta irrelevante, pero las fuertes convicciones religiosas de los responsables del menor son tomadas en consideración por los aplicadores del Derecho, atenuando la pena, no considerando relevante la agravante de parentesco e incluso provocando la predisposición a informar favorablemente un indulto para los responsables del menor" (Ministerio de Trabajo y Asuntos Sociales, II Informe de España sobre la aplicación de la Convención de Naciones Unidas sobre los Derechos de la Infancia, I, Madrid, 1999, p. 158).

55 STC 154/2002, de 18 de julio, FJ 9. 
«Al oponerse el menor a la injerencia ajena sobre su propio cuerpo, estaba ejercitando un derecho de autodeterminación que tiene por objeto el propio sustrato corporal - como distinto del derecho a la salud o a la vida - y que se traduce en el marco constitucional como un derecho fundamental a la integridad física (Art. 15० CE)m. ${ }^{56}$

Dice el Tribunal más adelante:

«No hay datos suficientes de los que pueda concluirse con certeza y así lo entienden las Sentencias ahora impugnadas- que el menor fallecido, hijo de los recurrentes en amparo, de trece ańos de edad, tuviera la madurez de juicio necesaria para asumir una decisión vital, como la que nos ocupan. ${ }^{57}$

Como puede verse, según el Tribunal Constitucional el menor no tiene madurez suficiente. Pero tampoco queda claro que si contara con suficiente juicio su oposición al tratamiento médico sería válida. Tal parece que ni aun en este caso, por lo que se dice a continuación:

«El reconocimiento excepcional de la capacidad del menor respecto de determinados actos jurídicos [...] no es de suyo suficiente para, por vía de equiparación, reconocer la eficacia jurídica de un acto [...] que, por afectar en sentido negativo a la vida, tiene, como notas esenciales, la de ser definitivo $y$, en consecuencia, irreparablem. ${ }^{58}$

Con el «reconocimiento excepcional de la capacidad del menor respecto de determinados actos jurídicos", el Tribunal se refiere a las capacidades que excepcionalmente reconoce el ordenamiento al niño, las que hemos referido en su oportunidad ${ }^{59}$ (como aquellas previstas en el Derecho aragonés, los derechos de la personalidad, la capacidad para contraer matrimonio, para ser oído). No obstante, a juicio del Tribunal, estas capacidades no pueden servir para, por vía de equiparación, dar eficacia jurídica a un acto que ponga en peligro la vida del niño. Con esto parece negar la

\section{Ibid.}

$57 \mathrm{Ibid}$., FJ 10.

$58 \mathrm{Ibid}$.

59 Cfr., supra, № 3. 
objeción de conciencia del menor, pero aparentemente no solo de este, por lo que leemos ahora:

«Es inconcuso [...] que la resolución judicial autorizando la práctica de la transfusión en aras de la preservación de la vida del menor (una vez que los padres se negaran a autorizarla, invocando sus creencias religiosas) no es susceptible de reparo alguno desde la perspectiva constitucional, conforme a la cual es la vida "un valor superior del ordenamiento jurídico constitucional" (SSTC 53/1985, de 11 de abril, y 120/1990, de 27 de junio). Además, es oportuno señalar que, como hemos dicho en las SSTC 120/1990, de 27 de junio, FJ 7, y 137/1990, de 19 de julio, FJ 5, el derecho fundamental a la vida tiene "un contenido de protección positiva que impide configurarlo como un derecho de libertad que incluya el derecho a la propia muerte». En definitiva, la decisión de arrostrar la propia muerte no es un derecho fundamental sino únicamente una manifestación del principio general de libertad que informa nuestro texto constitucional, de modo que no puede convenirse en que el menor goce sin matices de tamaña facultad de autodisposición sobre su propio ser». ${ }^{60}$

Con estos argumentos podría rechazarse también la objeción de conciencia en adultos, pues la protección de la vida como «un valor superior del ordenamiento jurídico constitucional" podría ser invocada en cualquier caso e imponer el tratamiento médico que busca preservarla. Esto significaría un cambio en la aparente tendencia hacia el respeto, bajo ciertas circunstancias, a la objeción de conciencia a tratamientos médicos en adultos, que parecen reflejar fundamentos del Tribunal Constitucional contenidos en Sentencias como la 120/1990 (FJ 7), 137/1990 (FJ 5) y 166/1996 (FJ 2), que ya hemos citado en este trabajo.

De otro lado, el Tribunal Constitucional parece asemejar el riesgo de pérdida de la vida al que puede enfrentarse el objetor de conciencia, con un supuesto de suicidio, pues cita las sentencias donde negó la existencia de un pretendido «derecho a la propia muerte» (120/1990, de 27 de junio, FJ 7, y 137/1990, de 19 de julio, FJ 5). ${ }^{61}$ Esta postura se enfrenta a

60 STC 154/2002, de 18 de julio, FJ 12.

61 Este criterio jurisprudencial fue seguido por la Audiencia Provincial de La Coruña (Auto de 19 de noviembre de 1996), al desestimar el pedido de un enfermo a fin de que 
aquel sector de la doctrina que opina que la objeción de conciencia a los tratamientos médicos no constituye un atentado contra la propia vida o la salud, conforme hemos mencionado líneas arriba.

El Tribunal Constitucional concluye diciendo:

«la exigencia a los padres de una actuación suasoria o de una actuación permisiva de la transfusión lo es, en realidad, de una actuación que afecta negativamente al propio núcleo o centro de sus convicciones religiosas. $Y$ cabe concluir también que, al propio tiempo, su coherencia con tales convicciones no fue obstáculo para que pusieran al menor en disposición efectiva de que sobre él fuera ejercida la acción tutelar del poder público para su salvaguarda, acción tutelar a cuyo ejercicio en ningún momento se opusieron». ${ }^{62}$

El Tribunal llega a conclusión semejante a la de la Audiencia Provincial de Huesca que absolvió a los padres: obligarles a convencer a su hijo para que consienta la transfusión, vulnera la libertad religiosa de éstos. Por lo demás, los progenitores no se opusieron a la orden judicial que disponía la transfusión. De esta forma, el Tribunal otorga el amparo solicitado y, en consecuencia, reconoce que se ha vulnerado el derecho fundamental de libertad religiosa de los padres, por lo que anula la sentencia condenatoria del Tribunal Supremo.

En esta Sentencia, el Tribunal Constitucional parece negar que el menor, independientemente de su madurez, esté en capacidad de formular objeción de conciencia a un tratamiento médico que le resulta vital, pues, aun cuando el ordenamiento le dé capacidades especiales en determinados actos concretos, no es posible con ello respaldar un acto que puede afectar en sentido negativo su vida, de modo irreparable.

se autorice judicialmente a su médico de cabecera que le suministre un tratamiento que le produzca la muerte y que ello no se entienda como ayuda al suicidio. En apoyo de esta tesis del Tribunal Constitucional puede citarse también la sentencia del Tribunal Europeo de Derechos Humanos en el caso Pretty c. Royaume-Uni, de 29 de abril de 2002, $\mathrm{N}^{\circ} 40$.

62 STC 154/2002, de 18 de julio, FJ 15. 